\title{
A PROSPECTIVE STUDY ON CLINICOPATHOLOGICAL \& RADIOLOGICAL EVALUATION OF PAROTID TUMOURS IN A TERTIARY CARE CENTRE
}

\section{Dr K. Vani \\ Dr K. Meghana \\ Dr Mohammad Hafeez Shaik \\ Dr B. Haricharan \\ Dr Ammireddy Sreenivas Reddy}

\section{Dr P. Vinay*}

Professor \& HOD, GMC \& GGH Kadapa, Andhra Pradesh, India - 516002.

Postgraduate, GMC \& GGH Kadapa, Andhra Pradesh, India - 516002.

Assistant Professor, GMC \& GGH Kadapa, Andhra Pradesh, India - 516002.

Postgraduate, GMC \& GGH Kadapa, Andhra Pradesh, India - 516002.

Postgraduate, GMC \& GGH Kadapa, Andhra Pradesh, India - 516002.

Associate Professor, GMC \& GGH Kadapa, Andhra Pradesh, India - 516002. ${ }^{*}$ Corresponding Author

ABSTRACT Background: Salivary gland tumours are relatively rare clinical entities encountered in the frequent dayto-day clinical practice. They exhibit a wide variety of behaviour and widely diversified histology. Proper management of these tumours require an accurate diagnosis by the pathologist, correct clinical correlation by the surgeon. With this background, we have conducted a study on the incidence, age, gender, clinical features of parotid swellings, histological distribution, the efficacy of FNAC as a diagnostic modality, the role of ultrasound and MRI in the diagnosis and various treatment modalities in the management of parotid swellings and their outcome in our institute.

Methods: Our study was a prospective study conducted on 60 patients over a period of 20 months from August 2018 to March 2020. All patients were evaluated by taking proper history, thorough clinical examination, routine laboratory investigations and specific investigations like FNAC, MRI, USG and biopsy.

Results: The mean age of presentation in our study was 35.73 years. Seventy percent of tumours were pleomorphic adenoma, malignant mixed tumours constituted 13\%, Warthin's neoplasm constituted 7.01\%, Basal cell adenoma, Oncocytoma and Acinic cell carcinoma each of these tumours constituted 3.33\%. All the patients presented with swelling (100\%) in the parotid region, $46.67 \%$ patients presented with pain in swelling, out of which majority were benign. Pain occurred in $100 \%$ of the patients with malignant tumours and only in $36 \%$ of the patients with benign tumours. No patient presented with features of facial nerve paralysis, fungating mass or cervical lymphadenopathy. On FNAC, 56 were reported as benign ( 50 cases were reported as benign and remain six were reported as malignant on HPE) remaining 4 cases were reported as malignant. Similar results were obtained on ultrasound. Fifty-one cases were reported as benign and remaining 9 cases were reported as malignant on MRI. Superficial parotidectomy was done in $83.33 \%$ of cases, the remaining were treated with conservative total parotidectomy. No radical parotidectomy and radical neck dissection (RND) were done.

Conclusion: Parotid tumours were commonly noticed in the 5th decade of life, males were predominantly affected. Pleomorphic adenoma is the most common tumour encountered. Malignant mixed tumours were most commonly observed malignant tumour followed by Acinic cell carcinoma. Parotid swelling is the most common presenting complaint followed by pain. Histopathological examination was more accurate when compared to FNAC. Superficial parotidectomy was the most commonly performed procedure.

KEYWORDS : Salivary gland, parotid tumour, superficial parotidectomy, total conservative parotidectomy, radical neck dissection.

\section{BACKGROUND}

Salivary gland tumours are relatively rare clinical entities encountered in the frequent day-to-day clinical practice. Salivary gland tumours occur in all age groups and both sexes. They exhibit a wide variety of behaviour and widely diversified histology. Proper management of these tumours requires an accurate diagnosis by the pathologist, correct clinical correlation by the surgeon. With this background, we have conducted a study on the incidence, age, sex, clinical features of parotid swellings, histological distribution, the efficacy of FNAC as a diagnostic modality for the detection of parotid swellings, the role of ultrasound and MRI in the diagnosis of parotid swelling and various treatment modalities in the management of parotid swellings and their outcome in our institute.

\section{METHODS}

Our study was a prospective study conducted on 60 patients who attended the out-patient Department of Surgery, Government General Hospital, Kadapa, over a period of 20 months from August 2018 to March 2020. All patients were evaluated by taking proper history, thorough clinical examination, routine laboratory investigations and specific investigations like FNAC, MRI, USG, Biopsy. Depending on the diagnosis, different surgical procedures were performed and the outcomes were studied.

\section{Inclusion Criteria}

1. Patient's age $>18$ years.

2. Those who gave consent to be included in the study.

3. Those who presented with a parotid tumour (benign or malignant).

4. Those who were fit for surgery.

\section{Exclusion Criteria}

1. Patient age $<18$ years.

2. Parotid swellings other than tumours.

4. Those who did not give consent for study.

\section{RESULTS}

Age \& Gender Distribution:

In the present study, parotid tumours most commonly involved the 5 th decade of life accounting to $30 \%$ of study population i.e., 18 cases. Overall mean age of presentation was 35.73 years. The mean age for benign tumours was 37.6 years and 
50.7 years for malignant tumours. Thirty-six (60\%) patients were males, and 24 (40\%) were females with M: F ratio of 1.5:1. Benign tumours were common in males (M: F-3:2). There was no gender predilection in malignant tumours (M: F-1:1).

Incidence of benign and malignant parotid tumours:

Out of 60 cases, 50 were benign tumours and 10 were malignant tumours. Distribution of various types of tumours is as follows:

Table 1: Incidence Of Benign And Malignant Parotid Tumours

\begin{tabular}{|l|l|l|l|}
\hline S.no & Type of tumour & $\begin{array}{l}\text { Number of } \\
\text { patients (n-60) }\end{array}$ & Percentage \\
\hline 1 & Pleomorphic adenoma & 42 & 70 \\
\hline 2 & Warthin's tumours & 4 & 6.67 \\
\hline 3 & Basal cell adenoma & 2 & 3.33 \\
\hline 4 & Oncocytoma & 2 & 3.33 \\
\hline 5 & Malignant mixed tumour & 8 & 13.33 \\
\hline 6 & Acinic cell carcinoma & 2 & 3.33 \\
\hline
\end{tabular}

Side of the parotid

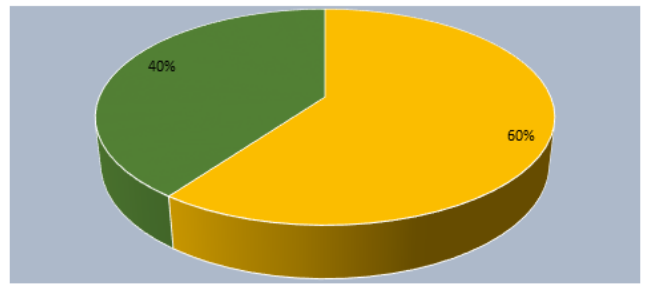

- Left side = Right side

Chart 1: Distribution Of Side Of The Parotid Involved

Table 2: Clinical Presentation Of Parotid Tumours

\begin{tabular}{|l|l|l|}
\hline Signs and Symptoms & No. of cases & Overall \% \\
\hline Swelling & 60 & 100 \\
\hline Pain & 28 & 46.67 \\
\hline Deep lobe enlargement & 4 & 6.66 \\
\hline Fixity to Masseter/Mandible & 4 & 6.66 \\
\hline Fungating mass & 0 & 0 \\
\hline Symptoms of facial palsy & 0 & 0 \\
\hline Cervical lymphadenopathy & 0 & 0 \\
\hline
\end{tabular}

Investigations:

Role of Fine Needle Aspiration Cytology (FNAC), Histopathological Examination (HPE), Ultrasonogram (USG) \& Magnetic Resonance Imaging (MRI)

In the present study, all the 60 cases subjected to FNAC, Ultrasound and MRI were reported as parotid tumours. Out of 60 cases subjected to FNAC, 56 were reported as benign and remaining 4 cases as malignant. Among the 56 cases which were benign on FNAC, histopathological examination revealed 6 to be malignant. Fifty-six cases were reported as benign, and the remaining 4 cases as malignant on ultrasound. Fifty-one cases were reported as benign and the remaining 9 cases as malignant on MRI. Fifty cases were reported as benign and the remaining 10 as malignant on HPE.

\section{Type Of Surgical Treatment Adopted In The Study:}

In our study, Surgery was performed in all patients, the type of surgery was chosen according to clinical impression, FNAC and per-operative findings. Out of 60 patients, Superficial parotidectomy was done in 50 cases (83.33\%), the remaining ten patients were treated with conservative total parotidectomy (16.67\%). In this study, radical parotidectomy and RND were not done in any of the patients. Radiotherapy was given postoperatively to 5 patients with a malignant tumour of the parotid gland. Out of these, four patients had a Malignant mixed tumour, and the other one had Acinic cell tumour. One patient who received radiotherapy developed xerostomia, which was treated conservatively. No patient with the benign disease of the parotid was given radiotherapy. No patient was given chemotherapy.

\section{Complications:}

Out of 60 patients, 28 patients developed postoperative complications. Postoperatively 14 (23.33\%) patients developed facial nerve weakness; among them, ten patients had pleomorphic adenoma, two patients had malignant mixed tumour and two patients had Warthin's tumour. Out of 14 patients who developed facial nerve weakness, 6 patients improved over 3-6 months, permanent facial nerve weakness occurred in 8 patients. Among these, 4 patients underwent lateral tarsorrhaphy to prevent eye complications. Facial nerve repair was not done in any patient. Wound infection was noticed in 8 patients (13.33\%), and parotid fistula was seen in 4 patients $(6.66 \%)$ with pleomorphic adenoma who had undergone superficial parotidectomy, which healed spontaneously within six months. Frey's syndrome was noticed in 2 patients (3.3\%). No postoperative death was encountered in this study.

\section{DISCUSSION}

The incidence of parotid swellings was most commonly seen in the 5 th decade which accounted for $30 \%$ (18 cases) of the total cases. The mean age of incidence of parotid tumours in our study was 35.73 years. This is almost similar to a study conducted by $\mathbf{A} \mathbf{R}$ Arshad et $\mathbf{a l}^{1}$, where the mean age of incidence was 40 years. This is in contrast to a study conducted by $\mathbf{S}$ Venkatesh et $\mathrm{al}^{2}$, who observed a mean age of incidence of 48.58 years for parotid tumours.

In our study, benign parotid tumours were commonly seen in the 4th and 5th decades of life, whereas malignant parotid tumours were seen frequently in the 5 th decade. The mean age of incidence of benign parotid tumours in our study was 37.6 years. This is similar to observations made by Jimsha Vannathan Kumaran et $\mathrm{al}^{3}$ and $\mathrm{A} \mathrm{R}$ Arshad et $\mathrm{al}^{1}$., where the mean age of incidence was 39.5 years and 40 years respectively.

The mean age of incidence for malignant tumours was 50.7 years in the present study. This is similar to observations made by Jimsha Vannathan Kumaran et $\mathrm{al}^{3}$ and A R Arshad et al ${ }^{1}$, where the mean age of incidence was 48.5 years and 50 years, respectively. This is in contrast to studies done by Shafkat Ahmad et $\mathrm{al}^{4}$. and Narinder Singh et $\mathrm{al}^{5}$, where the mean age of incidence of malignant parotid tumours was 42.4 years in both the studies.

Parotid tumours showed a male predominance in our study with M: F ratio of 1.5:1. S Venkatesh et al $^{2}$ and Shafkat Ahmad et $\mathrm{al}^{4}$ noted the same male preponderance, with a male-tofemale ratio of 1.3:1 and 1.17: 1 respectively. This is in contrast to other studies like those of Lalwani $\mathrm{AK}^{6}$, where females were affected more. Jimsha Vannathan Kumaran et $a l^{3}$ observed a slight overall female predominance with a male-to female ratio of 1:1.3. However, A R Arshad et al $^{1}$. noted that there was no significant difference between the number of males compared to female patients (1:1).

Benign tumours of parotid gland showed a male predomin ance in our study with male to female ratio of 1.5: 1. However, there is no gender predominance for malignant tumours of parotid in our study. E.S.DiomA.ThiamA et $\mathrm{al}^{7}$. in their study observed that benign parotid tumour affected both sexes comparably with male to female ratio of $1: 1.05$. Only Akkari's ${ }^{8}$ series stands out, reporting male predominance. The M: F 
ratio of the benign tumours was 1:1.17, whereas that of the malignant tumours was 1:3 in a study conducted by Narala Srivani et $\mathrm{al}^{9}$.

In our study, we observed that all patients presented with swelling $(100 \%)$ in the parotid region which was consistent with studies of R Ashok Reddy et $\alpha^{10}{ }^{10}$, S Venkatesh et $\alpha l^{2}$. and Ademar Takahama Junior et $\mathrm{l}^{11}$.

Pain, which was the second most common symptom occurred in $60 \%$ of the patients, which was quite contrary to the observations made by R Ashok Reddy et al $^{10}{ }^{\text {., }}$, where the pain was seen in only $16.67 \%$ of the patients. Pain, which occurred in $100 \%$ of the patients with malignant tumours was similar to the observations of $\mathbf{R}$ Ashok Reddy et $\mathrm{al}^{10}$. S Venkatesh et $\mathrm{al}^{2}$. also noted that pain in parotid gland was the second most common symptom and is more common in malignant tumours than in benign tumours. However, pain which was noticed in $60 \%$ of the patient in our study was seen only in $13.56 \%$ of the patients in $\mathbf{S}$ Venkatesh et al $^{2}$. series.

No patients in our study presented with cervical lymph node metastasis and as well as that of $R$ Ashok Reddy et $\mathbf{~ a l}^{10}$. Deep lobe enlargement was seen in $6.66 \%$ in this series which is in contrast to that of $\mathbf{S}$ Venkatesh et al $^{2}$, where superficial lobe was involved in $76.27 \%$ of cases, the ratio of superficial to deep lobe was 5.6:1.

In our study, among the all benign tumours, pleomorphic adenoma constituted $84 \%, 8 \%$ tumours were Warthin's tumour, $4 \%$ were basal cell adenomas and remaining $4 \%$ were oncocytomas. Among the malignant tumours, malignant mixed tumours constituted $80 \%$, and the remaining $20 \%$ of tumours were Acinic cell carcinomas. Hareesh G. S. R et al ${ }^{12}$ study shows pleomorphic adenoma constituted 25 cases (83.33\%) and Warthin's tumour 4 cases $(13.33 \%)$. Ungari et al ${ }^{13}$ study shows the pleomorphic adenoma (74.5\%) Shashikala et $\mathrm{al}^{14}$ study shows $71.42 \%$ are pleomorphic adenomas. Laura J. Orvidas et $\mathrm{al}^{15}$ study shows pleomorphic adenoma (22.9\%) and hemangioma (10.2\%). The most common malignant lesions were mucoepidermoid carcinoma (6.8\%) and acinic cell carcinoma (3.4\%).

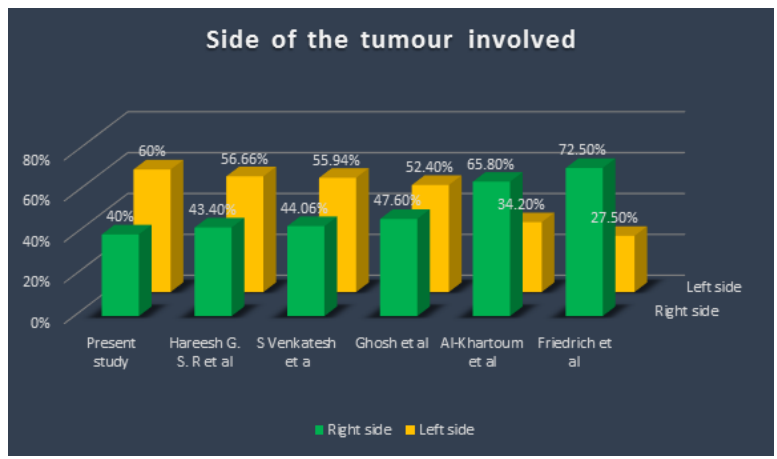

Chart 2: Side of the tumour

Manish Sharma et al ${ }^{16}$ conducted a study in 32 cases, FNAC of the swelling was done, $4(12.5 \%)$ cases were diagnosed as non-neoplastic, $23(71.8 \%)$ as benign, and 5 (15.6\%) were malignant. Correlation of FNAC and HPE was available in all the 32 cases. FNAC correctly diagnosed 29 cases, out of which 24 cases were benign, and 5 cases were malignant. In the present study, out of 60 cases which were subjected to FNAC 56 (93.3\%) were reported as benign remaining 4 (6.7\%) cases were reported as malignant. All 56 cases who reported as benign in FNAC were sent histopathological examination, in that 50 cases were reported as benign and remaining ten were reported as malignant.

In the present study, all 60 cases subjected to Ultrasound, of which $56(93.3 \%)$ cases were reported as benign and remaining $4(6.7 \%)$ cases were reported as malignant. S Wu et $\mathrm{al}^{17}$. study shows 271 patients who underwent parotidectomy, $229(85 \%)$ had benign tumours, 33 (12\%) had malignant tumours, and 9 had the chronic inflammatory disease (3\%). Mohammed et al $^{18}$. studied 242 patients, of whom $183(75.6 \%)$ had benign neoplasms, 51 (21.1\%) had malignant tumours, and $8(3.3 \%)$ had inflammatory or lymphatic lesions.

In the present study, all 60 cases were subjected to MRI, of which 51 cases were reported as benign, and the remaining 9 cases were reported as malignant. Inohara $\mathrm{H}$ et $\mathrm{al}^{19}$. conducted a retrospective study and took 81 patients of parotid mass lesions ( 60 benign and 21 malignant) who had undergone MRI preoperatively.

\section{CONCLUSION}

Parotid tumours most commonly noticed in the 5th decade of life, the mean age of occurrence of benign tumours was 37.6 years, and for malignant tumours was 50.7 years. Males were predominantly affected when compared to females for benign parotid tumours. No gender differentiation was observed in the incidence of malignant parotid tumours. Swelling was the most common presenting complaint followed by pain. Pleomorphic adenoma (70\%) was the most common tumour as well as the most commonly encountered (84\%) benign tumour. Among the malignant parotid tumours, Malignant mixed tumours (80\%) were most commonly observed, followed by Acinic cell carcinoma. Left side parotid was most commonly involved. Histopathological examination was more accurate when compared to FNAC. Among USG \& MRI, MRI is the better investigation modality. Superficial parotidectomy is the gold standard for benign tumours involving the superficial lobe of parotid. For those malignant tumours which are not locally advanced total conservative parotidectomy is a good option. Facial nerve weakness was the most common complication noticed followed by wound infection. Adjuvant radiotherapy can be offered to those parotid tumours which are large, high grade and those having positive resection margin. Strong recommendations cannot be made in the management of parotid tumors because of rarity of the tumour, diversity in histology and lack of large series.

\section{REFERENCES}

1. A R Arshad, FRCS Parotid Swellings: Report of 110 Consecutive Cases Med J Malaysia Vol 53 No 4 Dec 1998

2. S Venkateshl, Teerthanath Srinivas2, S Hariprasad3 Year: 2019 | Volume: 9 Issue :1 | Page: 103-109, Parotid gland tumours: a 2-year prospective clinicopathological study.

3. Jimsha Vannathan Kumaranl, Mariappan Jonathan Daniell, Mithunjith Krishnan2, Sruthi SelvamlDOI: 10.4103/srmjirds.srmjrds 3 19.Year :2019 Volume :10 | Issue :1| Page: 1216 Salivary gland tumours: An institutional experience.

4. Shafkat Ahrnad; Mohammad Lateef; Rouf Ahmad CLINICOPATHOLOGICAL STUDY OF PRIMARY SALIVARY-GLAND TUMORS IN KASHMIR JKPractitioner 2002; 9(4): 231233.

5. Narinder Singh K.S.Mehadratta and sathyanand. Study of salivary gland tumours. Indian Journal of Surgery 193-206.May 1968.

6. Lalwani AK. Current Diagnosis and Treatment in Otolaryngology-Head and Neck Surgery. 3rd ed. Pennsylvania, New York: The McGraw-Hill Companies 2008.

7. E.-S.DiomA.ThiamA.TallM.Ndiaye.ToureR.Diouf, European Annals of Otorhinolaryngology, Head and Neck DiseasesVolume 132, Issue 1, February 2015, Pages 9-12.

8. K. Akkari, S. Chnitir, A. Mardassi, et al.Tumeurs parotidiennes: à propos de 43 cas J Tun ORL, 18 (2007), pp. 29-33View Record in ScopusGoogle Scholar.

9. Narala Srivanil, Shyamala Srujana2, Syeda Shahista3, O. Shravan Kuma The spectrum of salivary gland tumours - A five-year study Vol. 3, Issue 7, July 2016.

10. R Ashok Reddyl, T S R S V Rajyalaxmi Godadevi2 Clinical Study and Management of Parotid Tumors International Journal of Scientific Study | July 2016 | Vol 4 | Issue.

11. Ademar Takahama JuniorI; Oslei Paes de AlmeidaII; Luiz Paulo Kowalski Parotid neoplasms: analysis of 600 patients attended at a single institution Braz. j. Otorhinolaryngology. (Impr.) vol.75 no.4 São Paulo July/Aug. 2009 http://dx.doi.org/10.1590/S1808-86942009000400005.

12. Hareesh G. S. R.1, Prabhakar Naidu Pulipati prospective study of clinical presentation, management, and postoperative complications of benign parotid swellings International Surgery Journal | July 2019 | Vol 6 | Issue 7 Page 2318.

13. Ungari C, Paparo F, Colangeli W, Iannetti G, parotid gland tumours. Eur Rev Med Pharmacol Sci. 2008: 12:321-5.

14. Shashikala V, Sonia Rani P.B, Alister J Victor Clinicopathological study of 
Salivary Gland Tumors. Int J Biomed Res. 2016;7(9):621-3.

15. Laura J. Orvidas, MD: Jan L. Kasperbauer, MD; Jean E. Lewis, MD; et Kerry D.

Olsen, MD; Timothy G. Lesnick, MS Pediatric Parotid Masses Author Affiliations Article Information Arch Otolaryngol Head Neck Surg. 2000;126(2):177-184. DOI:10.1001/archotol.126.2.177.

16. Manish Sharmal, Neeru Bala2, Sumeet Angral3, Megha Kapoor4, Mohit Goel FNAC of Salivary Gland Lesions with Histopathological and Clinical Correlation International Journal of Oral Health and Medical Research | ISSN 2395-7387 | SEPTEMBER-OCTOBER 2015 | VOL 2 | ISSUE 3.

17. S Wu, G Liu, R Chen, and Y Guan Role of ultrasound in the assessment of benignity and malignancy of parotid masses Dentomaxillofac Radiol. 2012 Feb; 41(2): 131-135.

18. Mohammed F Asaria J, Payne RJ, Freeman JL. A retrospective review of 242 consecutive patients treated surgically for parotid gland tumours. J Otolaryngol Head Neck Surg 2008; 37:340-346 [PubMed] [Google Scholar.

19. Inohara H, Akahani S, Yamamoto Y, Hattori K. The role of fine-needle aspiration cytology and magnetic resonance imaging in the management of parotid mass lesions. Acta otolaryngological. 2008; 128: 1152-1158. Ref.: https://goo.gl/rTj4gJ. 